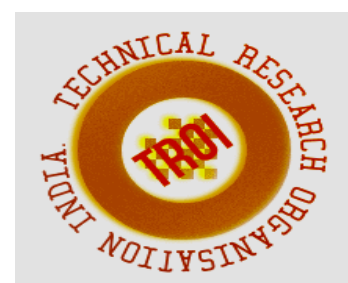

\title{
PROGNOSTIC ANTIPATCING CONTROLLER FOR ENERGY STORGE SYSTEM IN PV STABLIZING
}

\author{
R.Sivakumar ${ }^{1}$, Dr. P.Umasankar ${ }^{2}$ \\ ${ }^{1}$ PG Student, ${ }^{2}$ Associate Professor, \\ 11rsiva1978@gmail.com, ${ }^{2}$ umasankarp@mahendra.info \\ Mahindra Engineering College-Namakkal
}

\begin{abstract}
Nowadays The Photovoltaic (PV) system is developed in the power generation system connected to the grid. This grid tie with this PV system and it is used to generate power and utilize for consumer applications. The output is not efficient because of the saturation of the sunlight in the PV array and it's affected the power quality and stability of the system. To overcome this by adding the Energy Storage System in this model it to compensate the power loss in the PV system. The components of this system complement the characteristics of each other and tend to improve the power quality and stability of the system. However, a coordinated power management strategy among the individual components is crucial for reliable system operation under load and source power imbalances.
\end{abstract}

The proposed Prognostic Anticipating Controller Algorithm system, consists of DC synchronization with Photovoltaic and Energy Storage system is proposed to achieve improvement in the power quality and the losses is less when to the compare the existing method. The decentralized power sharing among the Photovoltaic and Energy Storage System is achieved through DC droop approach The critical parameters, such as state of charge, is also taken into account in order to ensure the health and stability of the Energy storage system. Further a secondary control is based on optimal operation of the hybrid system taking Energy storage system State of Charge into account. The proposed power management and control scheme are verified through real-time simulation carried out under wide variations in system condition.

Index Terms: Photovoltaic, Energy Storage, Solar cells, Power Quality.

\section{INTRODUCTION}

Solar system is one of the renewable energy source that recently increase in term of penetration level [1]. Nowadays the grid connected PV system utilization is increased and establishing the energy system. One of the major sources of power losses in such architecture arises when the PV generator is partially shaded by clouds or by surrounding obstacles such as in the case of urban environments[2].

The PV system is connect to the grid, in this grid tie PV system have the stochastic fluctuating of PV power is becoming a significant issue affecting the power quality and stability of the grid[3][10]. These isolated power systems at the distribution level are usually referred as autonomous

micro grid[4][9].For reliable operation of an autonomous

the source generation must meet the load demand while maintaining constant frequency and voltage at the consumer premises. Resulted indicated that voltage rise occurs in system with maximum installation of solar PV rooftop system[5][6].

The case study of solar rooftop system in other country has been reviewed. Opportunities and challenges of solar rooftop has been presented. Performance of the system under actual weather and topology[7][8]. 
A studied to estimation solar potential and analysis on performance and economic value has been reviewed Performance comparison between Monocrystalline and Polycrystalline in both pumping system and solar rooftop system has been presented. This mitigates the problem of synchronization during parallel operation of ac sources operating in droop mode which exhibits low frequency power oscillation The PV-battery and diesel generator act as a dc sources as they are connected to same dc link of inverter feeding ac load.

Hence, proposed DC synchronization technique adopts power clink voltage droop based decentralized power sharing control now, the load shared by the sources is based on the droop coefficient determined on their respective power rating and constitutes the primary control layer.

\subsection{Review Stage}

The power quality analysis of grid connected, PV system, and load. The grid's harmonics are affected from PV system and load. And the PV voltage is fluctuated because of the solar radiations this fluctuated PV output is affected the total power quality of this system. When the inverter power up to almost the rated power, meanwhile, percentages of harmonics are reduced and harmonics of load depend on the type of load.

Next, comparing harmonics, and found that harmonics of PV system hardly affect to load and harmonics of grid are more affected from load than PV system. That grid-connected inverter behaves as load when PV does not generate solar energy because it receives power from grid to verify the system connection.

The operation of passive components and switching equipment affects to the current harmonics generation because the system has low current flow. During PV does not generate solar energy, percentage of current harmonics decrease because current flow in the system increases.

\subsection{EXISTING \\ SYSTEM \\ BLOCK DIAGRAM}

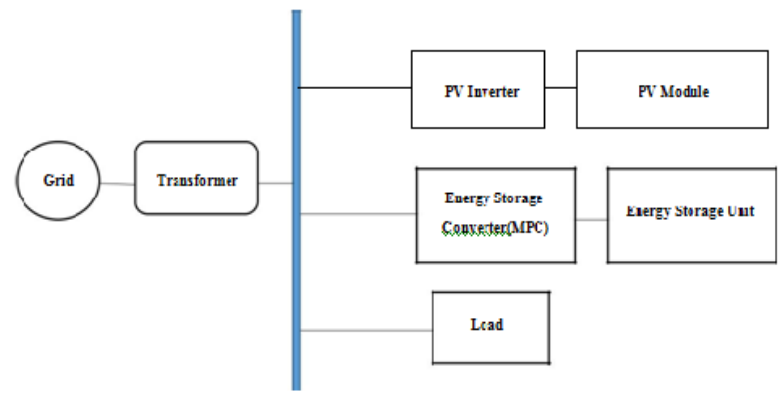

Fig.2.2.1 Existing system Block Diagram

In this existing system the grid and PV is connected to the ac bus, in this model the power quality problem is high and the storage system voltage is compensate the PV fluctuation. So the energy storage system voltage is boost and to give the AC bus and the load also connected to the AC bus.

In this PV system generates the dc voltage and it invert into DC to AC ant it give the supply of the grid tie system. The grid is connected to the transformer and it give to the AC bus, in any other fluctuation is occur in the AC bus it will compensate the ESS system

\subsection{PROPOSED SYSTEM}

This proposed method describes a distributed Prognostic Anticipating Controller Algorithm (PACA) of the system that uses for Controller solar power and improve the energy storage system .The proposed system consists of PV array, cascaded.

Therefore, the predictive control method proposed for the multifunctional inverter can compensate both of the grid current and reactive power required also transfers the $\mathrm{PV}$ power .This method provides simple control PACA algorithm, minimizes the number of sensors as the load and inverter currents are not measured, and provides ease of

practical implementation. The use of traditional linear control for power Controller in a cascaded PV architecture is perceived as a complicated scheme because of the requirement for additional cascaded proportional PACA based control 
loops to achieve overall system stability and the THD is $0.35 \%$.

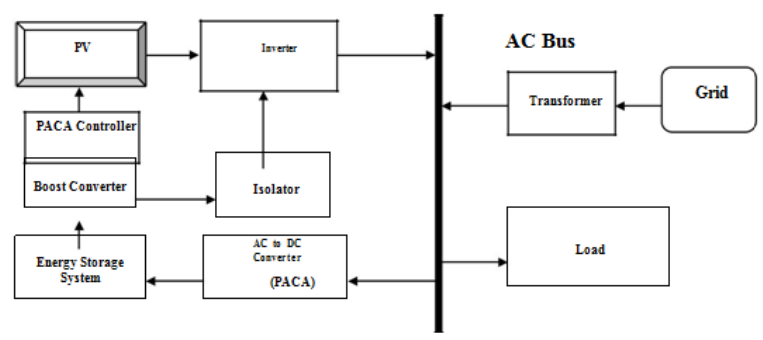

Fig.2.3 Proposed System Block Diagram

\subsubsection{PHOTOVOLTAIC ENERGY}

The word photovoltaic combines two terms photo means light and voltaic means voltage. The Photovoltaic energy is obtained from sun light in the form of solar energy. The sun light is made to be focused on solar panels which has the ability to convert the solar energy to an electrical energy. The conversion of solar energy to an electrical energy is done by solar cells of the solar panel.

A solar panel is a set of solar photovoltaic modules electrically connected and mounted on a supporting structure. A photovoltaic module is a packaged, connected assembly of solar cells. The solar panel can be used as a component of a larger photovoltaic system to generate and supply electricity in commercial and residential applications. Each module is rated by its DC output power under standard test conditions (STC), and typically ranges from 100 to 320 watts. The efficiency of a module determines the area of a module given the same rated output efficient module will have twice the area of a efficient module. A single solar module can produce only a limited amount of power; most installations contain multiple modules. A photovoltaic system typically includes a panel or an array of solar modules, an inverter, and sometimes a battery and/or solar tracker and interconnection wiring.

\subsubsection{EQUIVALENT CIRCUIT OF SOLAR CELL}

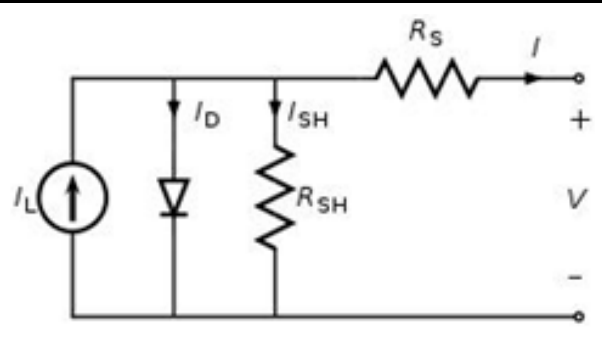

Fig.2.3.2 Equivalent Circuit of Solar Cell To understand the electronic behavior of a solar cell, it is useful to create a model which is electrical equivalent, and is based on discrete electrical components whose behavior is well known. An ideal solar cell may be modeled by a current source in parallel with a diode; in practice no solar cell is ideal, so a shunt resistance and a series resistance component are added to the model. The resulting equivalent circuit of a solar cell is shown on the left. Also shown, on the right, is the schematic representation of a solar cell for use in circuit diagrams.

\subsubsection{CONSTANT VOLTAGE}

The constant voltage method is the simplest method. This method simply uses single voltage to represent the VMP. In some cases this value is programmed by an external resistor connected to a current source pin of the control IC. In this case, this resistor can be part of a network that includes a NTC thermostat so the value can be temperature compensated. Reference 1 gives this method an overall rating of about $80 \%$. This means that for the various different irradiance variations, the method will collect about $80 \%$ of the available maximum power. The actual performance will be determined by the average level of irradiance. In the cases of low levels of irradiance the results can be better.

\subsubsection{OPEN CIRCUIT VOLTAGE}

An improvement on this method uses VOC to calculate VMP. Once the system obtains the VOC value, VMP is calculated

$$
\mathrm{V}=\mathrm{k} \times \mathrm{V} \text { MP OC }
$$

Sampling the VOC value can also help correct for temperature changes and to some degree changes in irradiance. Monitoring the input current can indicate when the VOC should be re-measured 
The $\mathrm{k}$ value is a function of the logarithmic function of the irradiance, increasing in value as the irradiance increases. An improvement to the VOC method is to also take this into account

\subsubsection{SHORT CIRCUIT CURRENT}

The short circuit current method uses a value of ISC to estimate IMP I $=\mathrm{k} x$ Isc

This method uses a short load pulse to generate a short circuit condition. During the short circuit pulse, the input voltage will go to zero, so the power conversion circuit must be powered from some other source. One advantage of this system is the tolerance for input capacitance compared to the VOC method.

\subsubsection{BOOST CONVERTERS}

The boost converters are used to convert the unregulated dc input to a controlled dc output at the desired voltage level. They generally perform the conversion by applying a dc voltage across an inductor or transformer for a period of time (usually in the $20 \mathrm{kHz}$ to $5 \mathrm{MHz}$ range) which causes current to flow through it and store energy magnetically, then switching this voltage off and causing the stored energy to be transferred to the voltage output in a controlled manner.

The output voltage is regulated by adjusting the ratio of on/off time. This is achieved using switched mode circuits whose elements dissipate negligible power. Pulse width modulation allows control and regulation of the total output voltage. It is considered as the heart of the power supply. Thus it will affect the overall performance of the power supply system.

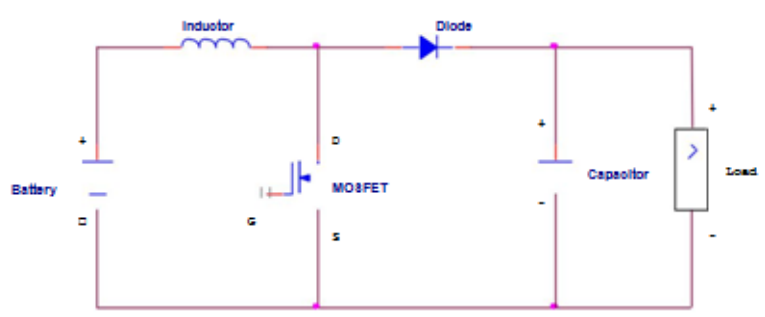

Fig.2.3.6 Boost Converter Circuit Diagram

\section{Duty Cycle:}

The duty cycle can be found using the following relation

$\mathrm{D}=1-\mathrm{Vi}$

\section{Inductor value:}

The value of inductor is determined using the following relation

$\mathrm{Lmin}=\mathrm{D}(1-\mathrm{D}) 2 \times \mathrm{R}$

An inductor is practically designed using the following parameters.

Formula for inductor design, $\mathrm{L}=(\mathrm{d} 2 \mathrm{n} 2) /(\mathrm{l}+$ $0.45 d)$

Required dimensions of inductor

Coil length, $\mathrm{l}=8.1 \mathrm{~cm}$

Diameter, $d=6.3 \mathrm{~cm}$

Inductance value required, $\mathrm{L}=151 \mu \mathrm{H}$

Number of turns, $n=64$

Where,

$\mathrm{L}$ is inductance in micro Henrys,

$\mathrm{d}$ is coil diameter in meters,

$l$ is coil length in meters, and

$\mathrm{n}$ is number of turns

\section{Capacitor value:}

The value of capacitor is determined from the following equation

$\mathrm{C}=\mathrm{DFs} \times \mathrm{R} \times \mathrm{Vr}$

Where,

$\mathrm{C}$ is the minimum value of capacitance,

$\mathrm{D}$ is duty cycle,

$\mathrm{R}$ is output resistance,

Fs is switching frequency, and

$\mathrm{Vr}$ is output voltage ripple factor.

Mode-1: When the MOSFET switch is in ON state (closed), the whole circuit will be divided into two loops one at the output side and another at the input side. The closed loop at input consisting of inductor gets charged by the current flowing through the circuit during this period. This current will increase linearly till the time the switch is in a closed condition. In the same time interval, inductor voltage is also high as it is not delivered to any load but to itself. A diode is off during this mode.

Mode-2: When the switch is in OFF state (Open), there will be a closed loop consisting of the power source, inductor, and RC load. The energy stored in the inductor during $\mathrm{ON}$ state is discharged to the RC load circuit through the diode. Thus inductor current is reducing linearly, 
charging the capacitor at the load side.

\subsubsection{INVERTER}

A power inverter is an electronic device or circuitry that changes direct current (DC) to alternating current (AC). An inverter converts the DC voltage to an AC voltage. In most cases, the input DC voltage is usually lower while the output AC is equal to the grid supply voltage of either 120 volts, or 240 Volts depending on the country.

The inverter may be built as standalone equipment for applications such as solar power, or to work as a backup power supply from batteries which are charged separately. There are different types of inverters based on the shape of the switching waveform.

These have varying circuit configurations, efficiencies, advantages and disadvantages. An inverter provides an ac voltage from dc power sources and is useful in powering electronics and electrical equipment rated at the ac mains voltage. In addition they are widely used in the switched mode power supplies inverting stages.

In this system we had proposed a specialized inverter circuit as Three Phase Cascaded $\mathrm{H}-$ Bridge Multilevel inverter. Recently, cascaded H-bridge multilevel inverter topology has gained interest from many researchers for PV system applications. Some of the best advantages of multilevel inverters are,

6) Producing the common mode voltage and reducing the stress of the motor and don't damage the motor.

7) These inverters can draw the input current with low distortion.

8) Selective harmonic elimination technique along with the multi-level topology results the total harmonic distortion becomes low in the output waveform without using any filter circuit.

Inverters are used to eliminate the bulky transformer required in case of conventional multi-phase inverters, clamping diodes required in case of diode clamped inverters and flying capacitors required in case of flying capacitor inverters. But these require large number of isolated voltages to supply the each cell.

\section{RESULTS AND DISCUSSION}

This proposed method of grid connected PV system utilizing MATLAB2017a software is to be used and simulate the system function and coordinated into the simulation model of a Prognostic Anticipating Controller Algorithm (PACA) controller system.

In the MATLAB/Simulink condition, using the capacities and Systems display library SIM Power to set up the entire PV system demonstrate, which is appeared in

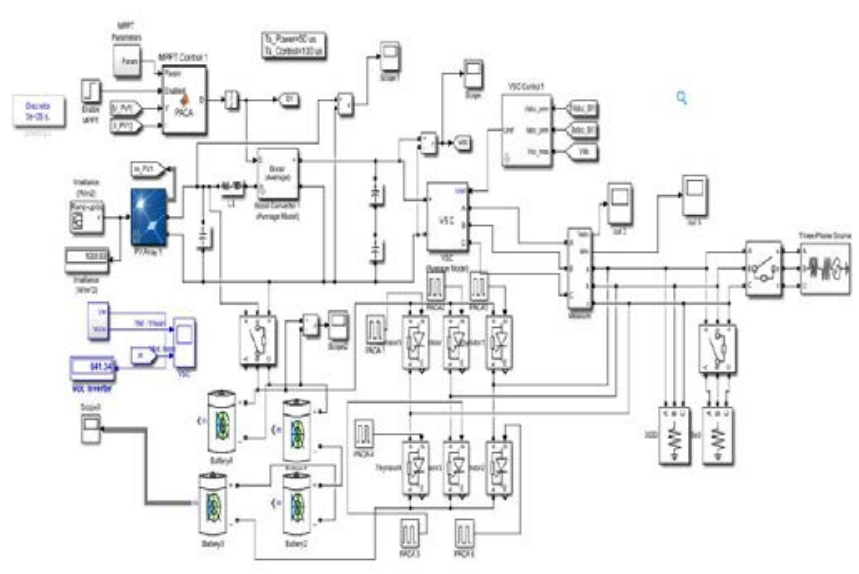

Fig.3 Final Simulink Model of the Proposed system

The overall Simulink model represents the grid-connected PV system. The PV sources of the leading renewable energy sources of the system.

The proposed system of the model is Prognostic Anticipating Controller Algorithm (PACA)Energy Storage System power it will show in the Fig.3.

The controller reproduction comes about are talked in following figures. And the system operation is to analysis 
Fig.3.1 Output voltage of the Proposed system

Fig.3.1 shows the output voltage of the proposed Prognostic Anticipating Controller Algorithm (PACA) system

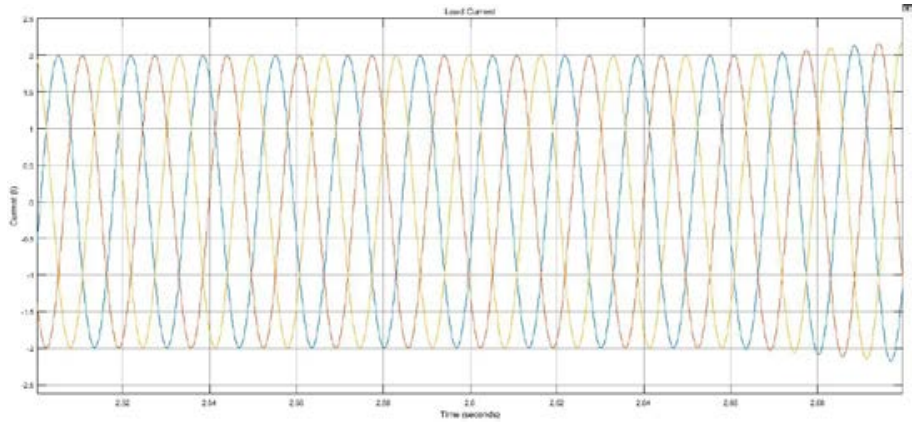

Fig.3.2 Output current of the proposed system

Fig.3.2 shows the output current of the proposed Prognostic Anticipating Controller Algorithm (PACA) system

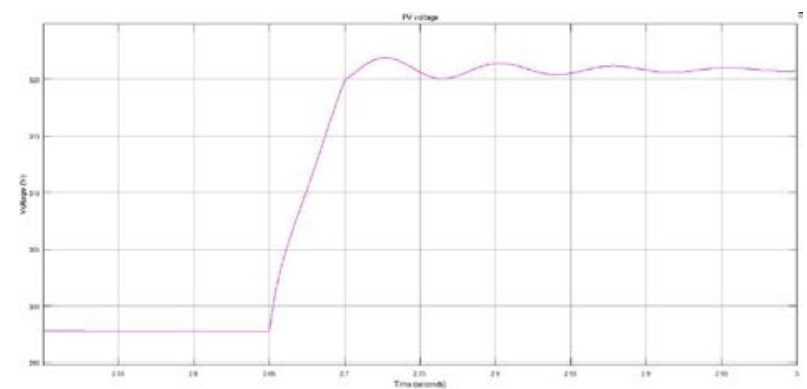

Fig.3.2 PV Voltage of the proposed system

Fig.3.2 PV voltage of the proposed Prognostic Anticipating Controller Algorithm (PACA) system

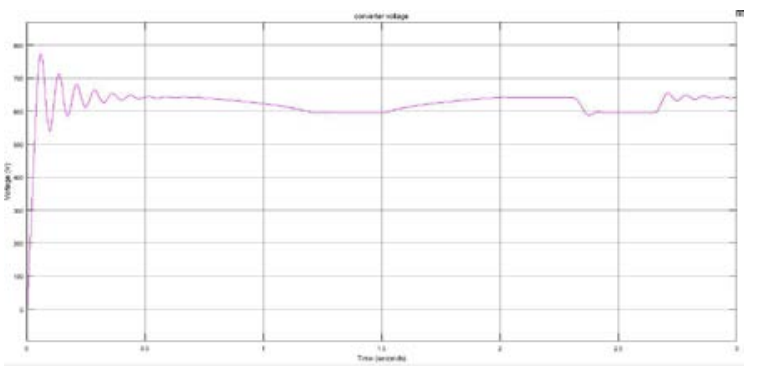

Fig.3.3 Boost converter output voltage

Fig.3.3 shows the boost converter output voltage of the proposed Prognostic Anticipating

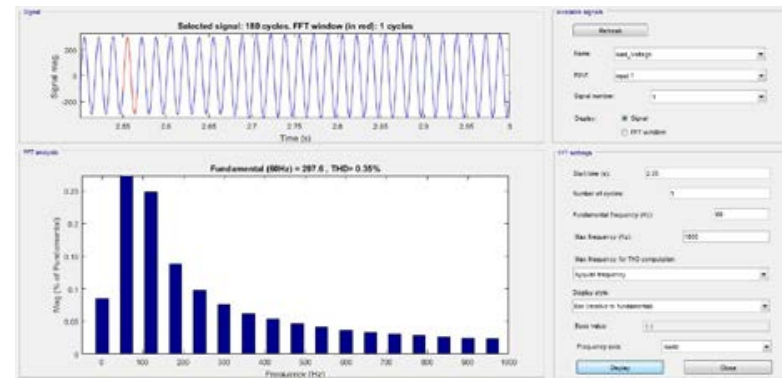

Fig.3.4 THD analysis

Fig.3.4 shows the THD analysis of the proposed system and it is essential to monitor the output voltage, in this system Total Harmonics Distortion is $0.35 \%$.

\begin{tabular}{|l|l|l|l|}
\hline \multicolumn{1}{|r|}{ Method } & Power Source & Converter Output & THD (\%) \\
\hline MPC & PV & 250 & 3.99 \\
\hline Proposed PACA & PV & 600 & 0.35 \\
\hline
\end{tabular}

\section{Table.1 Comparison analysis of THD and Output power}

Table. 1 shows the comparative analysis of the THD value and Converter output in the existing Model Predictive Control (MPC) and proposed Prognostic Anticipating Controller Algorithm (PACA) system

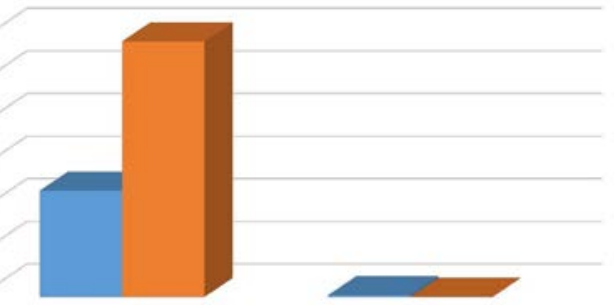

Fig.3.5 Comparison Chart

Fig.3.5 shows the comparison of output power in the proposed Prognostic Anticipating Controller Algorithm (PACA) system over the existing Model Predictive Control (MPC), and the Total Harmonics Distortion (THD) is reduced to the proposed system over the existing system.

\section{CONCLUSION}

The Power Quality Analysis impact of grid-connected photovoltaic power generation on power quality in distribution network. Summaries the requirement of power quality 
problems caused by photovoltaic power plant which connected in the user side. The proposed Prognostic Anticipating Controller Algorithm (PACA) system is used to improve the power quality of this system and the THD of this system is $0.35 \%$. This MATLAB simulates the whole system parameters. In one case of grid-connected photovoltaic generation and then analyzes it by developing models of photovoltaic generation and power grid belonged to the model. The power quality caused by grid side connected photovoltaic generation injecting into grid the photovoltaic generation system is reactive power regulation capability .In future work the algorithm is improved and develop the hardware of this system.

\section{REFERENCES}

[1] Arun Kumar Verma, Bhim Singh, "Harmonics and Reactive Current Detection of a Grid Interfaced PV Generation in Distribution System" in IEEE Transactions on Industry Applications, pp. 0093-9994, 2018.

[2] E. Scolari, L. Reyes-Chamorro, “A Comprehensive Assessment of the Short-Term Uncertainty of Grid-Connected PV Systems" in IEEE Transactions on Sustainable Energy,pp. 1949-3029, 2018.

[3] Yanyi Sun, Hong Yue, "Minimisation of Residential Energy Cost Considering Energy Storage System and EV with Driving Usage Probabilities" in IEEE Transactions on Sustainable Energy, pp. 1949-3029, 2018.

[4] Faicel EL Aamri, Hattab Maker, “A Direct Maximum Power Point Tracking Method for Single-Phase Grid Connected PV Inverters” in IEEE Transactions on Power Electronics, pp. 0885-8993, 2017.
[5] Yanjun Shi, Lu Wang, "Stability Analysis and Grid Disturbance Rejection for a 60kW SiC based Filter-less Grid-connected PV Inverter” in IEEE Transactions on Industry Applications, 2017.

[6] Nasif Mahmud, Ahmad Zahedi, “A cooperative operation of novel PV inverter control scheme and storage energy management system based on ANFIS for voltage regulation of grid-tied PV system" in IEEE Transactions on Industrial Informatics, pp. 1551-3203, 2016.

[7] Subhendu Dutta, Kishore Chatterjee, "A Buck \& Boost based Grid Connected PV Inverter Maximizing Power Yield from Two PV Arrays in Mismatched Environmental Conditions" in IEEE Transactions on Industrial Electronics, pp. 0278-0046, 2017.

[8] Anup Anurag, Nachiketa Deshmukh, "Integrated DC-DC Converter Based Grid-Connected Transformer less Photovoltaic Inverter with Extended Input Voltage Range” in IEEE Transactions on Power Electronics, pp. 0885-8993, 2017.

[9] Li Zhang, Kai Sun, “A Distributed Power Control of Series-connected Module Integrated Inverters for PV Grid-tied Applications” in IEEE Transactions on Power Electronics,pp. 0885-8993, 2017.

[10] Moin Hanif, Weidong Xiao, “Two Degrees of Freedom Active Damping Technique for LCL Filter-Based Grid Connected PV Systems" in IEEE Transactions on Industrial Electronics, pp. 0278-0046, VOL. 61, 2014. 